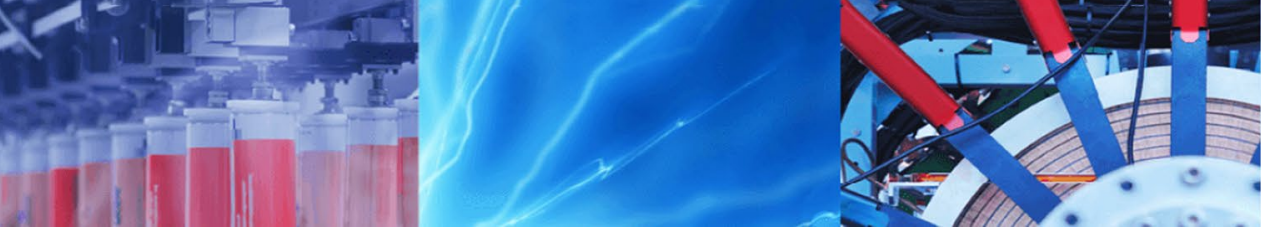

Research Article

\title{
Investigating the mechanical and insulation performance of waste eggshell powder/epoxy polymer for power insulation application
}

\author{
A. A. Abdelmalik ${ }^{1}$ M. O. Ogbodo ${ }^{1} \cdot$ G. E. Momoh ${ }^{1}$
}

(c) Springer Nature Switzerland AG 2019

\begin{abstract}
In an effort towards the optimization of materials for industrial application, composite technology has been identified to provide an effective way to improve the performance of insulating materials used in power system applications. Clay and synthesized metal oxide micro- and nanoparticles have been used as fillers in host polymer materials. In this study, the focus is on the development of composite polymeric insulation using particles from animal shell waste for use in electrical and electronic power systems. Epoxy composite samples were prepared with waste chicken eggshell powder and titanium oxide $\left(\mathrm{TiO}_{2}\right)$ nanoparticles, respectively. Mechanical (tensile strength) and dielectric properties were studied, and high-voltage AC was used to evaluate the variation in electrical conductance with percentage composition of the filler particles in the epoxy polymer matrix. This was done by monitoring the leakage current through the epoxy polymer composites under high-voltage stresses in the range of $0.5-5 \mathrm{kV}$. The two polymer composites' type has comparable loss tangent, but the eggshell powder-filled polymer samples displayed higher dielectric constant and lower electrical conductance at high voltage compared with the $\mathrm{TiO}_{2}$ nanoparticle-filled polymer composite samples. While the minimum conductance of $2.68 \times 10^{-9} \mathrm{~S}$ was obtained from the epoxy composite sample with $3 \mathrm{wt} \%$ eggshell particle loading, epoxy nanocomposite displayed a minimum conductance of $4.06 \times 10^{-9} \mathrm{~S}$ with $2 \mathrm{wt} \%$ titanium oxide loading. This is an indication that polymer composite with the eggshell particles may produce polymeric insulation that could be more resistant to leakage current.
\end{abstract}

Keywords Polymer composites · Dielectrics · Epoxy · High-voltage insulation · Eggshell waste · Natural filler

\section{Introduction}

Polymeric materials are among the most important components of electrical insulation, and epoxy family occupies a very important position. Epoxies are a class of thermoset materials used extensively in structural and specialty composite applications because they offer a unique combination of properties when compared with other thermoset resins. They are available in a wide variety of physical forms with different viscosity and can be processed to a wide range of geometries and application. Epoxies offer high strength, low shrinkage, excellent adhesion to various substrates for effective electrical insulation, chemical and solvent resistance, low cost and low toxicity. They are easily cured with a broad range of chemical species without the evolution of volatiles or by-products. Epoxy resins are also chemically compatible with most substrates and tend to wet surfaces easily, making them especially well-suited to composite application [1].

Epoxy-insulated devices are widely used in low- and medium-voltage components such as bus support insulators, enclosures for protective devices, fuse cut-outs, cable accessories, bushing and power module encapsulation. They have several advantages over conventional porcelain. They are lighter and non-brittle, do not break easily, are easy to handle and can be cast into various shapes. Their use eliminates the need for oil and maintenance issue that may arise from oil leakage $[2,3]$.

A. A. Abdelmalik, aaabdelmalik@gmail.com | 'Department of Physics, Ahmadu Bello University, Zaria, Nigeria.

SN Applied Sciences (2019) 1:1238 | https://doi.org/10.1007/s42452-019-1259-9 
Meanwhile, the need for improved polymeric insulation brings about the idea of composite dielectrics. This involves the addition of fillers (micro-/nanosized) in dielectric materials to create composite materials. Composite materials are generally defined as a multiphase material in which the phase distribution and geometry are controlled in order to optimize one or more properties [4]. The intention of producing composite material is to make a material that combines the best properties. Several papers have reported progress made in the dispersion of additives (fillers) at low loading in polymers to produce composite dielectric materials [5].

Dielectric studies of epoxy polymer filled with microand nanoparticle show that the dispersion of nanoparticle in epoxy polymer matrix results in increased or reduced dielectric loss. Different types of particles have been used as fillers in the epoxy-based polymer composite. These include silica, carbon nanotubes, oxides of metals, graphene oxide, barium ferrite and clay [6-11]. Earlier work revealed that polymer micro- and nanocomposite materials have quite different dielectric behaviour. The microcomposite was reported to exhibit dielectric loss (loss tangent) that increases with frequency without any noticeable strong dispersion in the mid-frequency range $\left(10^{2}-10^{5} \mathrm{~Hz}\right)$. The nanocomposite on the other hand produced a loss tangent data that increased monotonically without any peaks at low frequency $\left(10^{-3}-10 \mathrm{~Hz}\right)$. This was reported to be an indication of relaxation processes involved in nanocomposites [12]. Singa et al. reported that dispersion of $\mathrm{TiO}_{2}$ microparticles in epoxy produced a composite material with relative permittivity and loss tangent (dielectric loss) that is higher than that of unfilled epoxy. The addition of $\mathrm{TiO}_{2}$ and $\mathrm{ZnO}$ nanoparticles in epoxy at low loading produced nanocomposite polymer with lower relative permittivity and loss tangent $(\tan \delta)$. They were found to have improved the dielectric and mechanical strength of the polymeric insulation. Epoxy nanocomposite systems with inorganic oxide fillers displayed some advantageous dielectric behaviours at low nanofiller loadings. The permittivity and $\tan \delta$ of the nanocomposites were found to be lower than that of microcomposites as well as unfilled systems (for few filler loadings) [13-15]. Nanofilled epoxy matrix was reported to have activation energy that suggested that the nanoparticles restrict chain movement. An observed increase in the real permittivity of microcomposite with decreasing frequency was reported to be associated with the microparticles due to Maxwell-Wagner interfacial polarization [16]. There is an indication that polymer composite with nanoparticles could produce a material with lower dielectric loss. Application of high field in polymeric insulation materials often lead to partial discharge, and continuous partial discharge activities could lead to the complete breakdown of the system. In evaluating the breakdown strength of nanoand micro-epoxy composite materials, a short-term electric field strength measurement of the neat epoxy, as well as the micro- and nanocomposites as a function of filler loading under DC conditions, shows that the nanocomposite displayed a better breakdown property. The epoxy nanocomposite displayed better breakdown strength at certain filler loading beyond which degradation sets in [9, 17].

While a number of metal oxide particles have been studied as filler for polymer composite, nanoparticles from clay were also considered as filler for epoxy polymer-based matrix. Aside from clay, there are other naturally occurring resources such as animal shells and eggshells that can serve as cheap resources as fillers for polymeric insulation. Animal shells have been identified as cheap sources to synthesize micro-/nanoparticles for industrial application [18]. Eggshells, a waste animal product with similar characteristics with calcite $\left(\mathrm{CaCO}_{3}\right)$, are among the cheap natural resources with composite metal oxides that can serve as filler for polymer composites. Its chemical composition consists of 76.99 wt $\%$ of $\mathrm{CaO}, 21.13 \mathrm{wt} \%$ of $\mathrm{C}$ and traces of $\mathrm{Na}_{2} \mathrm{O}, \mathrm{MgO}, \mathrm{P}_{2} \mathrm{O}_{5}, \mathrm{SO}_{3}, \mathrm{Fe}_{2} \mathrm{O}_{3}$, etc. $[19,20]$. It is a biodegradable material. It has also been suggested as a potential source of filler [19]. There were reports that it has been used to improve the mechanical strength of polymer composites. Pure calcium oxide and nanohydroxyapatite have been produced from waste eggshell to prepare polymer composite. The polymer composite was reported to have exhibited improved thermal and mechanical properties [21]. Meanwhile, there is no much available information on the dielectric and high-voltage insulation behaviour of eggshell powder-filled polymeric insulation. The idea behind this work is to produce fine powder from properly cleaned eggshell (animal waste) and study its influence on the mechanical, thermal and dielectric properties of the epoxy polymer in comparison. The result will be compared with data obtained from epoxy composite filled with $\mathrm{TiO}_{2}$ nanoparticle, a particle that has been studied extensively as filler for polymeric insulation.

\section{Materials and methods}

\subsection{Sample preparation}

Chicken eggshells were collected from cafeteria within Ahmadu Bello University Zaria, Nigeria. The samples were washed with water, removing the white membrane inside the eggshells and then left to dry. Subsequently, the eggshells were washed with acetone and methanol after which it was also left to dry. The eggshells were ground into powder with a ball milling machine and then sieved 
with a $75-\mu \mathrm{m}$ mesh sieve. Anatase titanium oxide nanoparticle of size 10-30 nm was obtained from Sky Spring Nanomaterials, USA. The surface morphology of the eggshell powder and $\mathrm{TiO}_{2}$ nanoparticles was studied using Phenom ProX Desktop scanning electron microscope (SEM) equipped with an energy-dispersive spectroscopy system. Agilent Cary 630 FTIR machine was used to identify the chemical constituents in the compound from the characteristic frequencies on the spectra.

The epoxy polymer was prepared from epoxy resin and hardener. West System 105 Epoxy Resin and 207 Special Clear Hardener were mixed in the ratio 3:1, respectively. First, the epoxy resin and the hardener were mixed using a magnetic stirrer for $3 \mathrm{~min}$ for each composition. The epoxy resin and the hardener were thoroughly mixed together for another $3 \mathrm{~min}$ at $27^{\circ} \mathrm{C}$ in a mixing cup. The epoxy was then placed in a vacuum oven for degassing. The degassed mixed liquid was transferred to the mould to produce a neat epoxy sheet of about $2 \mathrm{~mm}$ thick. The polymer composite was prepared by adding $1 \mathrm{wt} \%, 2 \mathrm{wt} \%$, $3 \mathrm{wt} \%, 4 \mathrm{wt} \%$ and $5 \mathrm{wt} \%$ of $\mathrm{TiO}_{2}$ nanoparticles and eggshell powder to the epoxy resin, and flat sheets of a polymer composite of about $2 \mathrm{~mm}$ thick were produced with the mould. The prepared samples are described in Table 1, and a picture of some of the samples is shown in Fig. 1.

\subsection{Surface morphology and dispersion of eggshell powder in polymer composites}

The microstructure of the polymer samples was studied using Phenom ProX Desktop scanning electron microscope (SEM) equipped with an energy-dispersive spectroscopy system. The samples were held on the sample holder using a double-sided carbon tape before putting them inside the sample chamber, and SEM was operated at an accelerating voltage of $15 \mathrm{kV}$, and the image was recorded.

\subsection{Tensile test}

The tensile test was performed using the Monsanto Motorized Automatic Recording Tensometer, type 'W' with serial number 9875 . The machine has two jaw clamps. The test

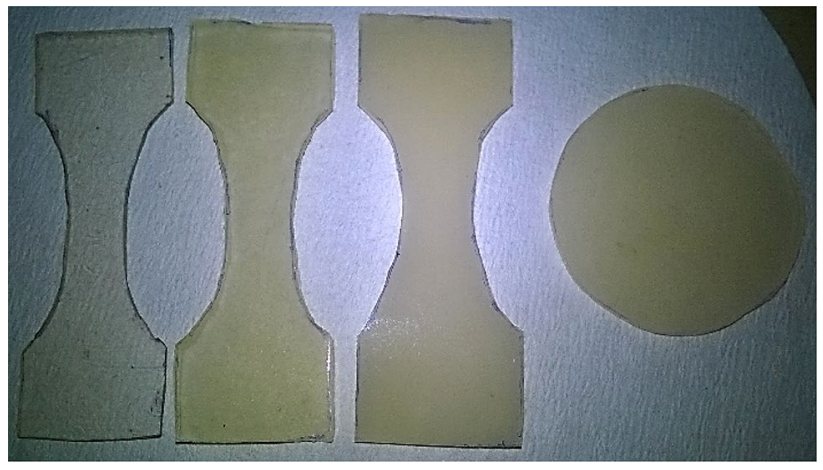

Fig. 1 Prepared samples in a circular (for electrical test) and dumbbell shapes (for mechanical test)

sample in dumb-bell shape was positioned on the jaws, and the clamp was used to grip the test sample. The wheel attached to the clamp was turned to increase the tension on the test sample until the sample breaks. The graph obtained from the test is analysed, and the obtained maximum force and cross-sectional area of the sample were used to calculate the sample's tensile strength (in MPa).

\subsection{Thermal conductivity test}

The thermal conductivity of the polymer samples was determined using Searle's method. The set-up was initially used to determine the thermal conductivity of materials with known thermal conductivity. The polymer samples were, respectively, placed in the sample chamber and heated at one end by the means of an electrical power supply. Water was made to flow through the apparatus, and it entered the tube at the end of the steam chamber and leaves at the end nearer to it. The power supply was switched on when the water was flowing, and the input current and voltage were recorded. The water starts to get hotter until a constant temperature difference is reached, and the water flow was adjusted so that the temperature difference is about $5^{\circ} \mathrm{C}$. Thermometers $\theta_{1}$ and $\theta_{2}$ placed where water was coming in and out were used to measure the temperatures of the outlet and inlet water. The temperatures $\theta_{1}$ and $\theta_{2}$ were recorded. The experiment was repeated three times for each sample to determine the

Table 1 Samples description

\begin{tabular}{|c|c|c|c|}
\hline \multicolumn{2}{|c|}{ Epoxy-titanium oxide nanocomposite } & \multicolumn{2}{|c|}{ Epoxy-eggshell powder composite } \\
\hline Code & Sample description & Code & Sample description \\
\hline ETiONC1 & Epoxy $+1 \% \mathrm{TiO}_{2}$ nanoparticle & EESMC1 & Epoxy $+1 \%$ eggshell powder \\
\hline ETiONC2 & Epoxy $+2 \% \mathrm{TiO}_{2}$ nanoparticle & EESMC2 & Epoxy $+2 \%$ eggshell powder \\
\hline ETiONC3 & Epoxy $+3 \% \mathrm{TiO}_{2}$ nanoparticle & EESMC3 & Epoxy $+3 \%$ eggshell powder \\
\hline ETiONC4 & Epoxy $+4 \% \mathrm{TiO}_{2}$ nanoparticle & EESMC4 & Epoxy $+4 \%$ eggshell powder \\
\hline ETiONC5 & Epoxy $+5 \% \mathrm{TiO}_{2}$ nanoparticle & EESMC5 & Epoxy $+5 \%$ eggshell powder \\
\hline
\end{tabular}




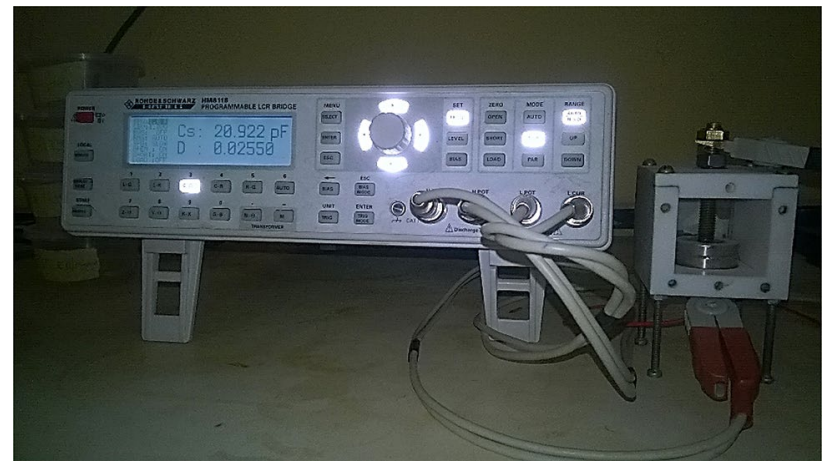

Fig. 2 Dielectric measurement test set-up

average value of the thermal conductivity of the samples [22].

\subsection{Dielectric analysis}

The dielectric properties of the samples were studied using Rhode \& Schwarz HM8118 programmable LCR Bridge, and a two-electrode test cell is shown in Fig. 2. The experimental set-up has a measurement accuracy of $0.05 \%$. Samples in circular shape were placed in the test cell connected to the LCR Bridge and $2 \mathrm{~V}$ applied. The capacitance and the loss tangent values were recorded within the frequency range of $20 \mathrm{~Hz}$ to $60 \mathrm{kHz}$. The relative permittivity (real part) of the samples was calculated using the expression:

$\varepsilon^{\prime}=C / C_{0}$

where $C_{0}=$ capacitance of the test cell in the air which is expressed as $C_{0}=\varepsilon_{0} A / d$, where $\varepsilon_{0}$ is the permittivity of vacuum ( air), $A=$ area and $d=$ distance. And, $C$ is the capacitance when the sample is placed between electrodes of the test cell [23].

\subsection{High-voltage leakage current measurement}

The test set-up put up for this work is shown in Fig. 3. The high-voltage supply is generated with REK RK2672AM high-voltage AC source. The RMS value of the applied voltage from the $A C$ source was monitored with a multimeter and a high-voltage probe (1:1000 V). A current limiting resistor, $R 1$, was connected in series with the test cell to avoid high peak current if a breakdown should occur. A protective resistor $R 2$ was placed between the test cell and the measuring instrument to prevent excessive current getting to the measuring instrument should a breakdown occur. And $R 3$ served as the measuring resistor. High voltages in the range of $0-5 \mathrm{kV}$ were applied at an interval of $0.5 \mathrm{kV}$ on the test sample, and conduction current from the sample was recorded with the data acquisition system. The

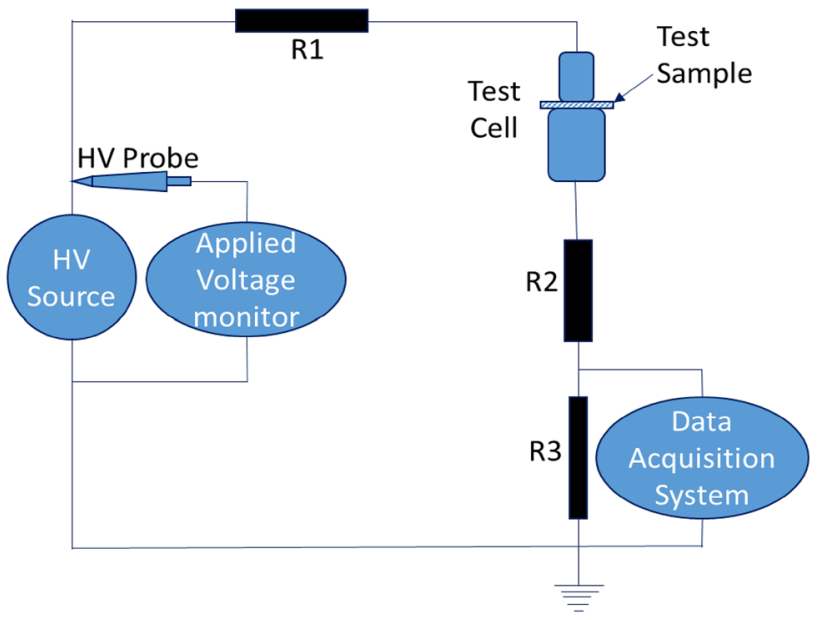

Fig. 3 Schematic diagram of the high-voltage experimental set-up

applied electric field was evaluated using the thickness of the sample.

\section{Results and discussion}

The scanning electron microscopy (SEM) image of the eggshell powder particles and $\mathrm{TiO}_{2}$ nanoparticles from Phenom ProX Desktop scanning electron microscope (SEM) equipped with an energy-dispersive spectroscopy system is shown in Fig. 4. Figure 4a shows the microstructure of the eggshell powder, while Fig. $1 \mathrm{~b}$ shows the microstructure of $\mathrm{TiO}_{2}$ nanoparticle obtained from Sky Spring Nanomaterials, USA. The micrograph of eggshell powder (Fig. 4a) revealed a surface of random-sized particles. The particles' average size was determined from the microphotograph. The eggshell powder has a range of particle size distribution. There are particles within the range of $0.5-5 \mu \mathrm{m}$, there are another set of particle sizes within the range of $10 \mu \mathrm{m}$, and there are other set of larger particles with sizes within $30-50 \mu \mathrm{m}$.

Agilent Cary 630 FTIR machine was used to identify the chemical constituents in the compound from the characteristic frequencies on the spectra. Figure 5 shows the FTIR spectra of the eggshell powder in the absorbance mode. The obtained spectra are similar to what was reported in an earlier publication, an indication that the chemical composition of eggshells is reproducible [24]. The weak band at $1796.6 \mathrm{~cm}^{-1}$ is assigned to $\mathrm{C}=\mathrm{O}$ bonds from carbonate. There appeared two well-defined infrared peaks at 1408.9 and $872.2 \mathrm{~cm}^{-1}$ which is attributed to the characteristic $\mathrm{C}-\mathrm{O}$ stretching and bending modes of calcium carbonate, respectively. The sharp peak at $711.9 \mathrm{~cm}^{-1}$ which appeared at the fingerprint region is related to $\mathrm{Ca}-\mathrm{O}$ bonds. The peak at $1796.6 \mathrm{~cm}^{-1}$ is among the common 
Fig. 4 SEM microstructure: a eggshell powder, $\mathbf{b} \mathrm{TiO}_{2}$ nanoparticles
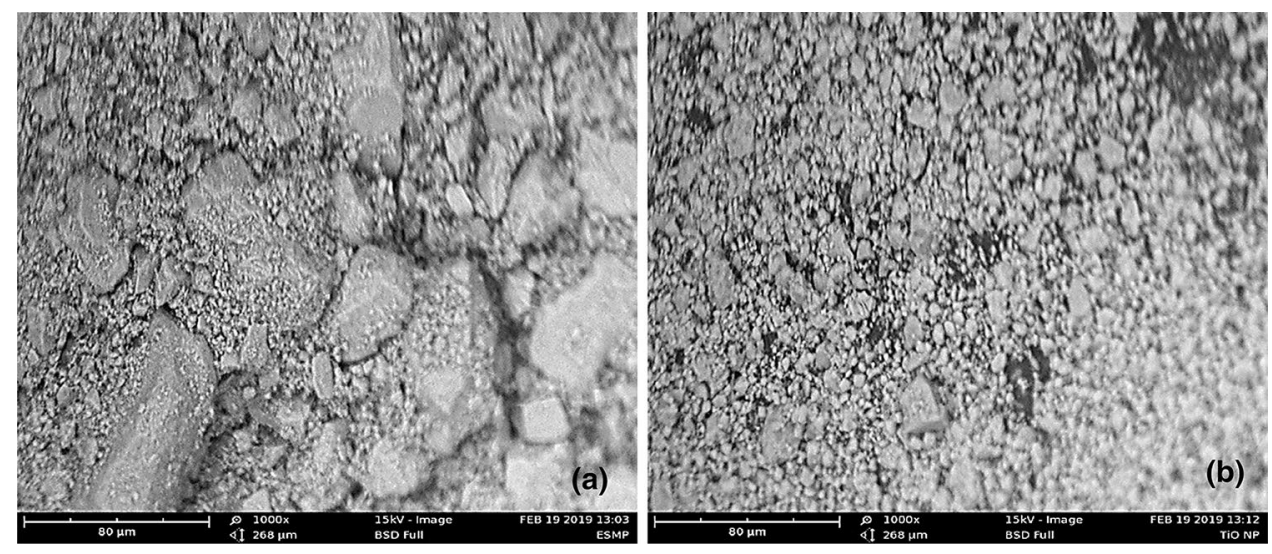

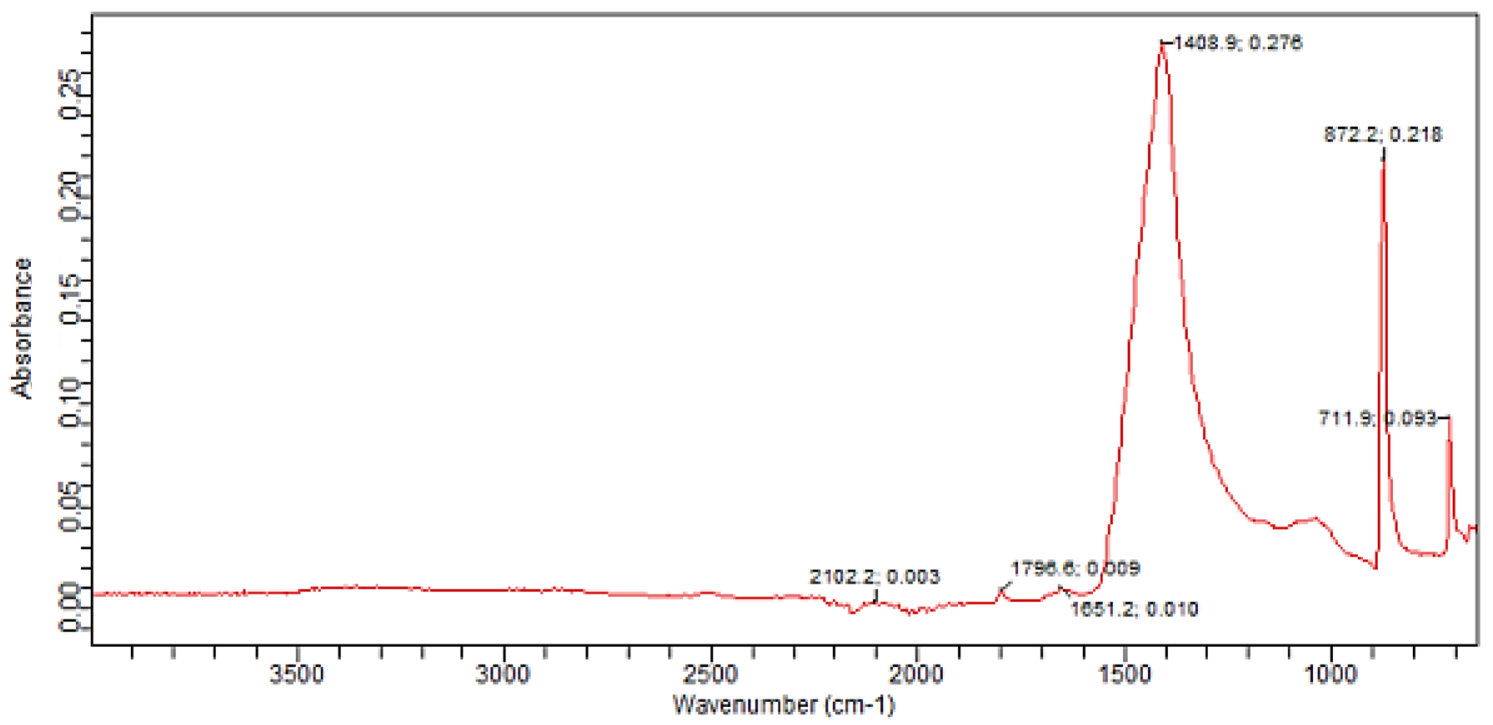

Fig. 5 FTIR spectra of eggshell powder

characteristic features of the carbonate ions in calcium carbonate $[25,26]$.

Figure 6 shows the microstructure from the scanning electron microscope (SEM) of some of the polymer samples. Figure 6a reveals the image of the neat epoxy polymer. The image did not display any trace of voids in the polymer. The issues of agglomeration/aggregation of micro- and nanoparticles in the polymer matrix are found in most methods used in the preparation of polymer composites. It became necessary to ascertain the state of the fillers in the composites. Figure $6 \mathrm{~b}, \mathrm{c}$ shows the image of the polymer composites with 2 wt $\%$ eggshell powder and $\mathrm{TiO}_{2}$ nanoparticles, respectively. The images show a homogeneously dispersed bright dot, an indication that the particles are well dispersed in the base polymer. Figure $6 \mathrm{~b}$ shows the SEM image of dispersed eggshell powder in epoxy with an average size of $200 \mathrm{~nm}$ and a larger particle or an agglomeration of the size $12 \mu \mathrm{m}$. Figure $6 \mathrm{c}$ shows the SEM image of $\mathrm{TiO}_{2}$ nanoparticles in epoxy with a number of agglomerations of the nanoparticles of an average size of $1 \mu \mathrm{m}$.

The tensile test results for the eggshell-epoxy and $\mathrm{TiO}_{2}$-epoxy composites samples are shown in Fig. 7. The tensile strength of the neat (unreinforced) epoxy sample was found to be about $22.23 \mathrm{MPa}$. The tensile strength of the epoxy composite with $\mathrm{TiO}_{2}$ nanoparticle increased rapidly to $37.67 \mathrm{MPa}$ with the addition of nanoparticles up to $2 \mathrm{wt} \%$. Further increase in the concentration of nanoparticle led to a decrease in the tensile strength of the composite. The addition of $3 \mathrm{wt} \%$ produced a tensile strength of $13.7 \mathrm{MPa}$. Beyond $2 \mathrm{wt} \%$, the material may have become brittle and resulted in failure with lesser tension. Meanwhile, the tensile strength of the epoxy composite with eggshell powder increased steadily with the addition of nanoparticles up to $4 \mathrm{wt} \% .2 \mathrm{wt} \%$ and $3 \mathrm{wt} \%$ of the powder produced tensile strength of $22.93 \mathrm{MPa}$ and $24.13 \mathrm{MPa}$, respectively. And an increase in the percentage concentration of the microparticle powder to $5 \mathrm{wt} \%$ 

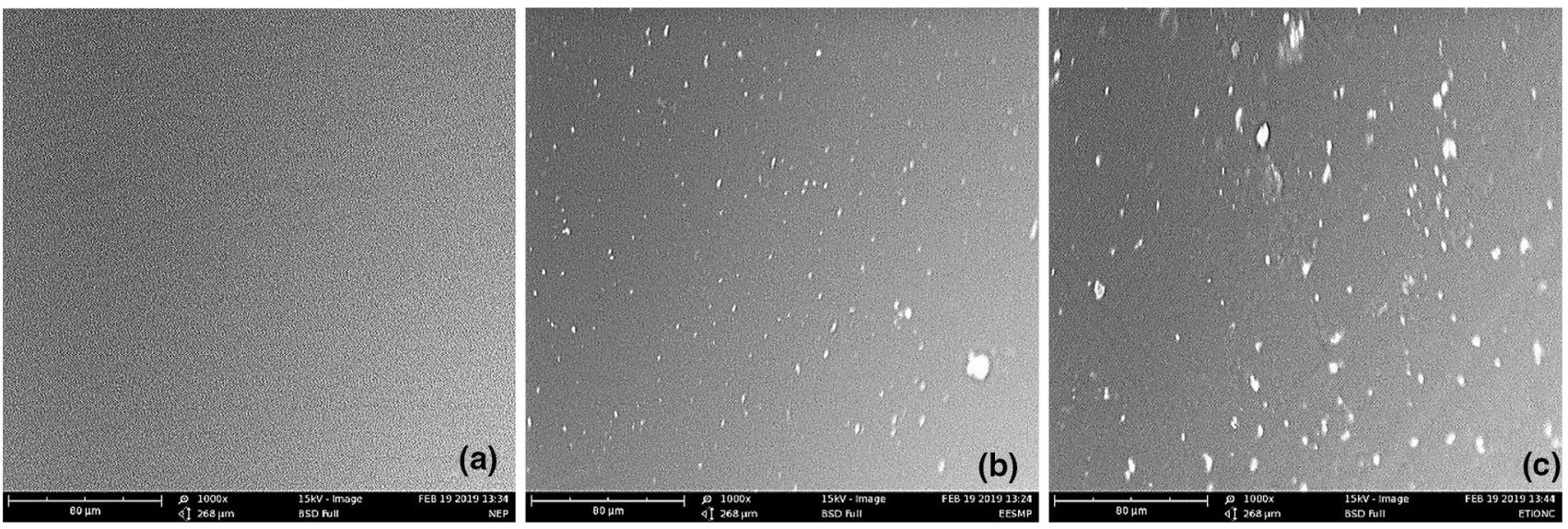

Fig. 6 SEM images: a neat epoxy, b epoxy $+2 \mathrm{wt} \%$ eggshell powder and c epoxy $+2 \mathrm{wt} \% \mathrm{TiO}_{2}$ nanoparticle

Fig. 7 Tensile strength of the epoxy composites

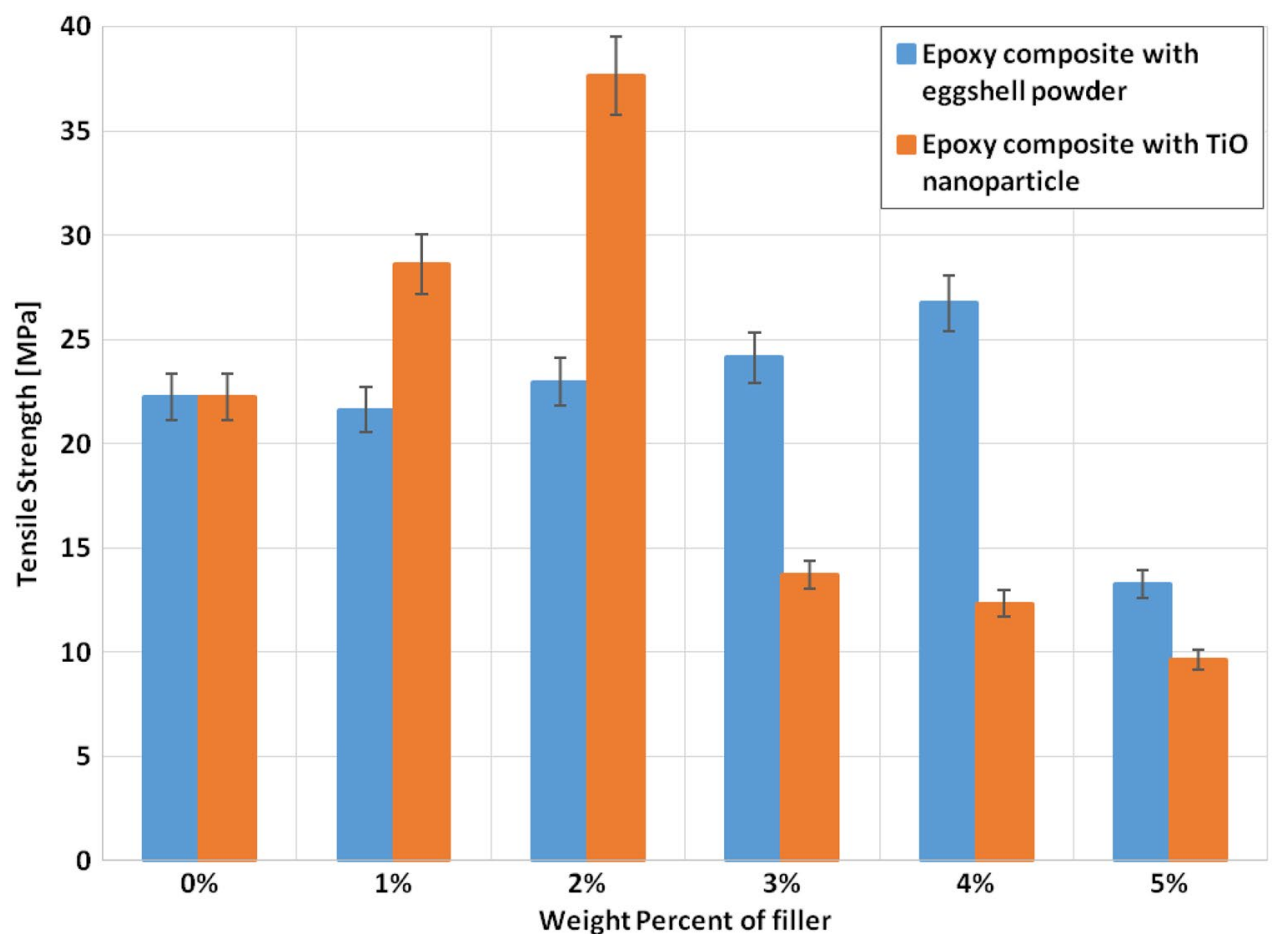

led to a decrease in the tensile strength of the composite. The tensile strength of the $1 \mathrm{wt} \%$ filled $\mathrm{TiO}_{2}$ nanocomposite was higher than the sample filled with $1 \mathrm{wt} \%$ eggshell microparticle. The dispersion of $2 \mathrm{wt} \%$ shows a similar increase. But increasing the concentration of the fillers to $3 \mathrm{wt} \%$ resulted in a drop in the tensile strength of $\mathrm{TiO}_{2}$ nanocomposite, while eggshell microcomposite continued its steady increase.

While the epoxy- $\mathrm{TiO}_{2}$ composite has the maximum tensile strength of $37.67 \mathrm{MPa}$ with $2 \mathrm{wt} \% \mathrm{TiO}_{2}$ nanoparticle, the epoxy-eggshell composite has a maximum tensile strength of $26.76 \mathrm{MPa}$ with $4 \%$ eggshell microparticles. Nanoparticles were said to favour the initiation of nanovoids leading to stress concentration in the adjacent matrix strands [27], thus leading to plastic yielding and fibrillation of the polymer matrix. The easy debonding of particles from the polymer matrix was reported to generate easy cavitation during mechanical loading. This results in the reduction in the effective stress for crazing. This phenomenon sometimes refers to as'nanoparticle modulated craze' acts as a source of additional toughness enhancement to the polymer composite. This is likely responsible for the significant improvement on the tensile strength of the polymer composite sample with $2 \mathrm{wt} \% \mathrm{TiO}_{2}$ nanoparticles. Meanwhile, the size of the voids inside the cavitated/fibrillated craze structure depends on the size of the 
nanoparticles or the agglomerates [27]. Increasing the content of the nanoparticle led to more particle agglomeration. The larger agglomerates tend to initiate voids that act as crack nuclei. Rapid crack propagation may produce brittle behaviour. Nanoparticle agglomeration may have resulted in the drop in the tensile strength of the polymer composite with the addition of $3 \mathrm{wt} \%$ of $\mathrm{TiO}_{2}$ as shown in Fig. 7. On the other hand, a gradual increase was observed on the tensile strength of the polymer composites with eggshell powder but with values lower than the tensile strength of the composites with $\mathrm{TiO}_{2}$. The density of $\mathrm{CaO}$ which is the dominant component of the eggshell powder is lower than the density of $\mathrm{TiO}_{2}$. This implies that the number of particles in the eggshell powder is lower than the number of $\mathrm{TiO}_{2}$ nanoparticles in the respective measured weight per cent. The particle size of the eggshell powder is bigger than that of $\mathrm{TiO}_{2}$ nanoparticles; as a result, larger voids may have been initiated. The resulting reduction in the effective stress for crazing is lower compared with that of nanoparticle and provides lower toughness enhancement to the polymer composite. This toughness enhancement provided by the number of particles and the initiated larger voids increases up till the addition of $4 \mathrm{wt} \%$ eggshell powder. The addition of $5 \mathrm{wt} \%$ may have resulted in large agglomerates that initiated voids that act as crack nuclei, and the resulting brittle behaviour through rapid crack propagation produced the recorded lower tensile strength. These results suggest that epoxy with titanium oxide will produce a polymer composite with better mechanical strength compared with the eggshell powder.

The plot of thermal conductivity of the samples with various contents of the powders is shown in Fig. 8. The thermal conductivity of the neat epoxy is comparable to the literature values [28]. The dispersion of the powders shows an increase in thermal conductivity of epoxy. The thermal conductivity increased with an increase in percentage composition of the powder. The thermal conductivity of the epoxy filled with $3 \mathrm{wt} \%, 4 \mathrm{wt} \%$ and $5 \mathrm{wt} \%$ eggshell powder displayed higher thermal conductivity compared with that of the $\mathrm{TiO}_{2}$-filled epoxy. This may be linked to the higher thermal conductivity of $\mathrm{CaO}$ which has the highest composition in eggshell.

The relative permittivity and dielectric loss (loss tangent) of the samples measured were within the frequency range of $20 \mathrm{~Hz}$ to $60 \mathrm{kHz}$ as shown in Figs. 9 and 10. The relative permittivity was calculated from the measured capacitance using Eq. 1. The relative permittivity was generally observed to decrease with increase in frequency within the studied frequency range as shown in Fig. 9. But the loss tangent of all the samples decreases with increasing frequency between 20 and $200 \mathrm{~Hz}$ with a slope of about -1 on a log-log plot. But the loss tangent remained nearly constant for all the samples in the frequency range of $200 \mathrm{~Hz}$ to $60 \mathrm{kHz}$ as shown in Fig. 10. Generally, the addition of fillers resulted in an increase in the dielectric constant (relative permittivity) with an increase in filler concentration. The dielectric constant increased continuously with an increase in filler concentration. Dielectric constant of the eggshell-filled epoxy composite samples has relatively higher values compared with those of the $\mathrm{TiO}_{2}$-filled epoxy composite samples. Addition of $1 \mathrm{wt} \%$ and $2 \mathrm{wt} \%$ $\mathrm{TiO}_{2}$ filler to the base epoxy polymer resulted in a reduced dielectric loss with the $2 \mathrm{wt} \% \mathrm{TiO}_{2}$ particle-incorporated polymer composite having the least loss. Further addition
Fig. 8 Thermal conductivity of epoxy composites with various eggshell powder and $\mathrm{TiO}_{2}$ contents

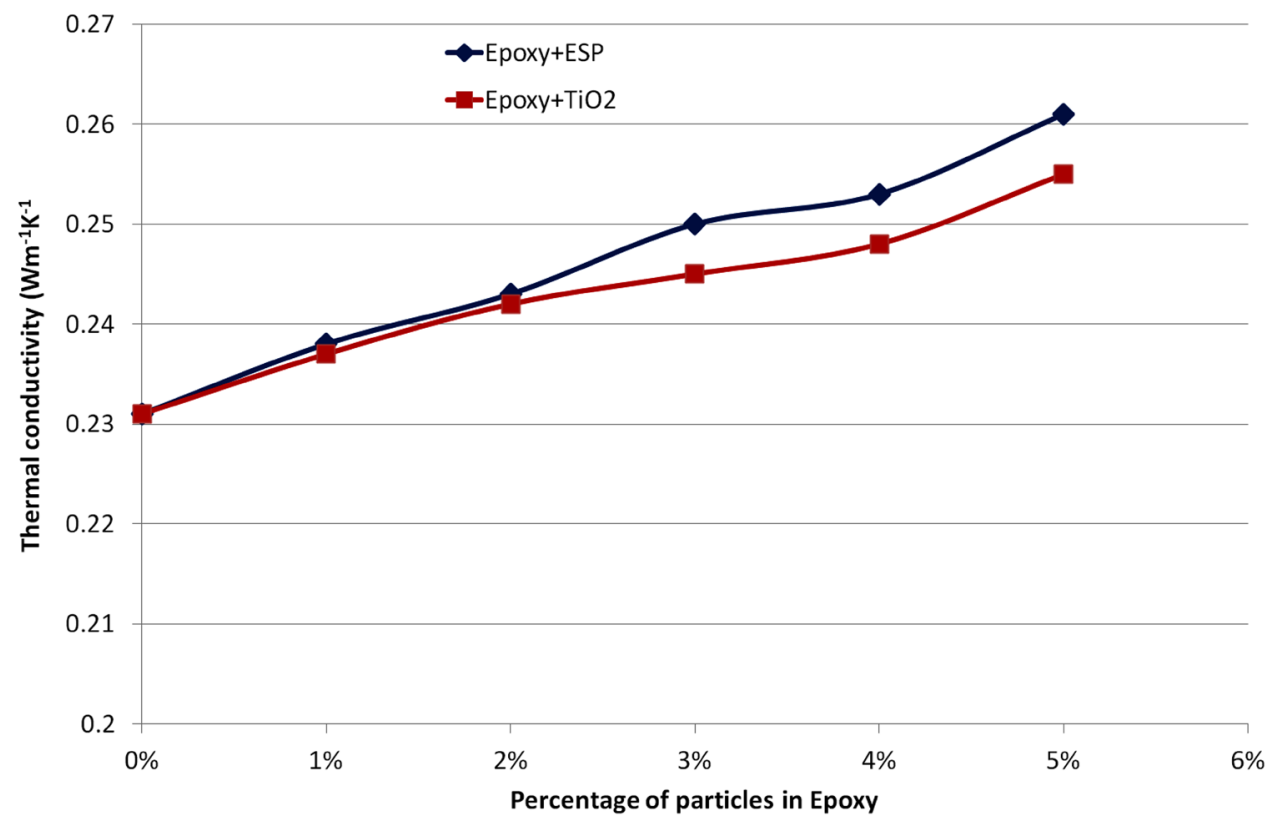

SN Applied Sciences A SPRINGER NATURE journal 

relative permittivity versus frequencies from $20 \mathrm{~Hz}$ to $60 \mathrm{kHz}$ for a epoxy- $\mathrm{TiO}_{2}$ composite, b epoxy-eggshell powder composite
Fig. 9 Semi-log plot of real

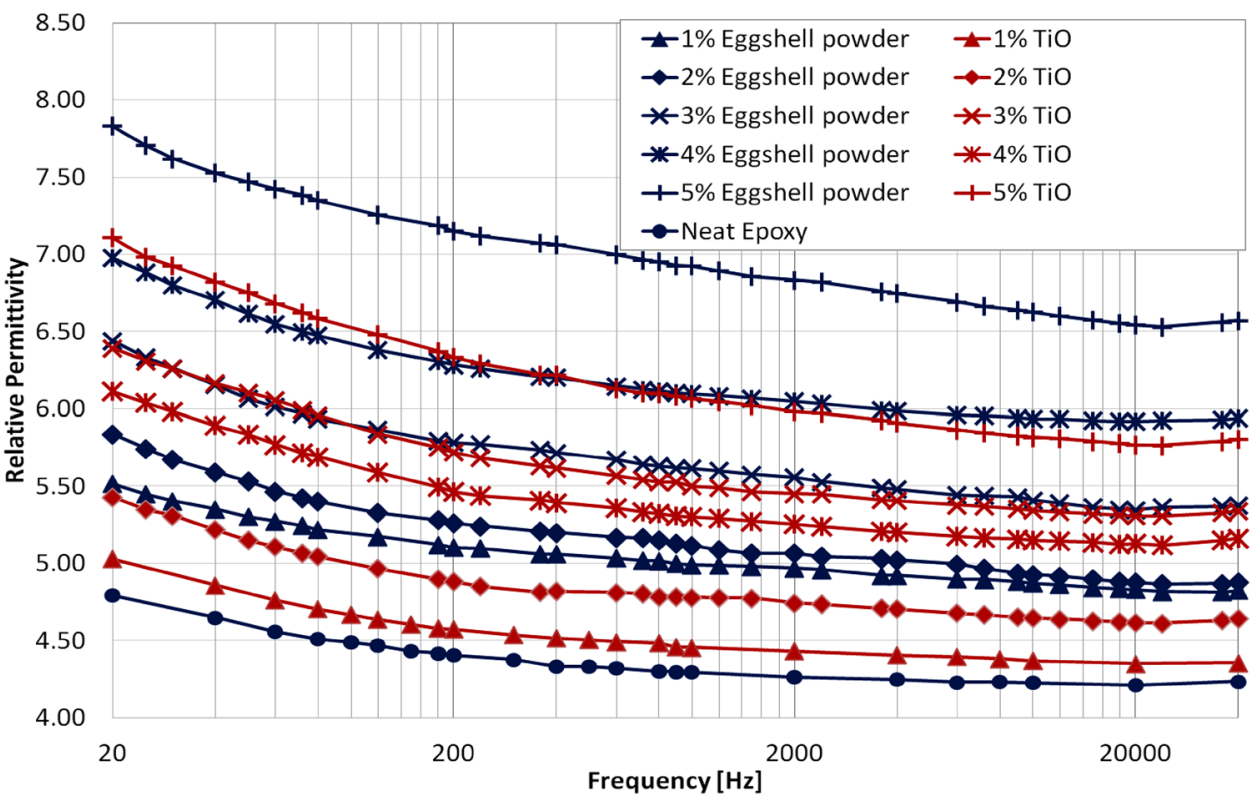

Fig. 10 Semi-log plot of loss tangent versus frequencies from $20 \mathrm{~Hz}$ to $60 \mathrm{kHz}$ for a epoxy- $\mathrm{TiO}_{2}$ composite, $\mathbf{b}$ epoxy-eggshell powder composite

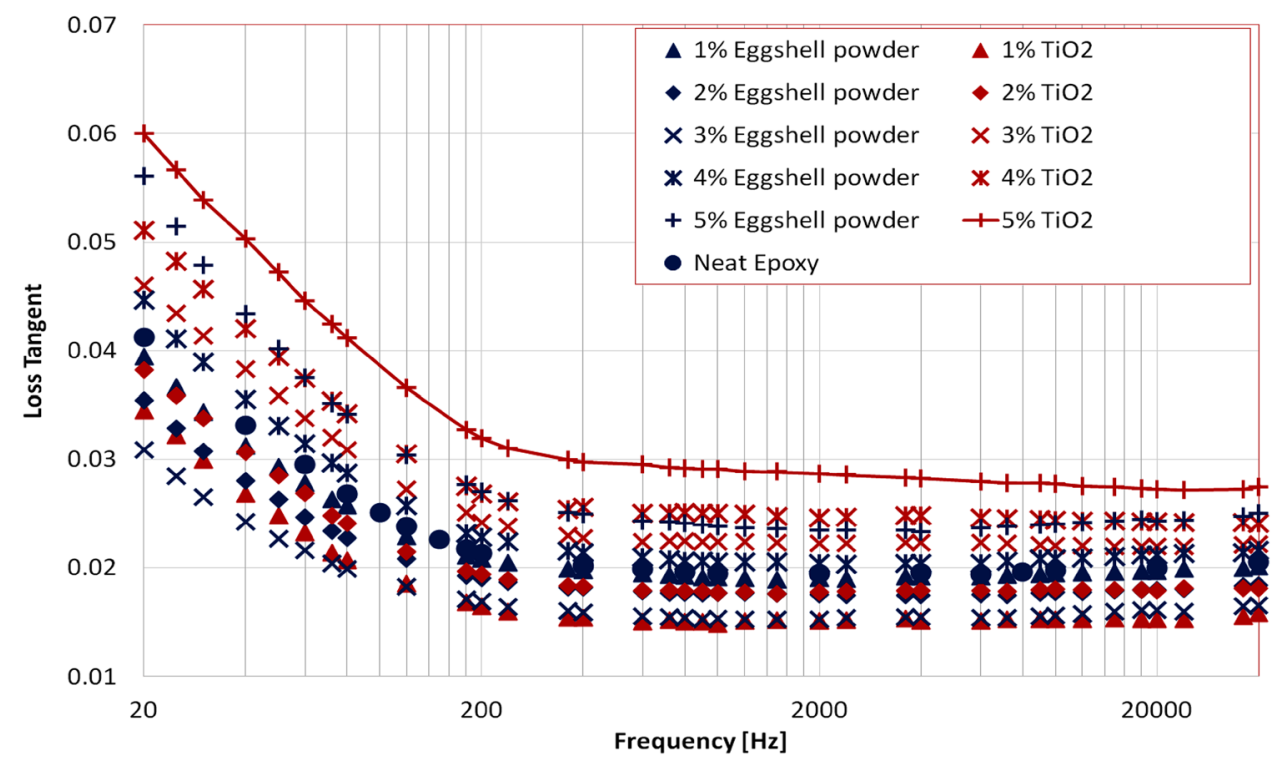

of $3 \mathrm{wt} \%, 4 \mathrm{wt} \%$ and $5 \mathrm{wt} \% \mathrm{TiO}_{2}$ nanosize filler concentrations resulted in greater loss higher than that of the host polymer.

On the other hand, there was observed steady decrease in loss tangent with the addition of $1 \mathrm{wt} \%, 2 \mathrm{wt} \%$ and 3 wt\% eggshell particles to the host epoxy polymer with the $3 \mathrm{wt} \%$ eggshell particles-incorporated polymer composite having the least dielectric loss. However, the addition of $4 \mathrm{wt} \%$ and $5 \mathrm{wt} \%$ eggshell particles to the host polymer resulted in increased dielectric loss. The measured dielectric constant for the neat epoxy at $1 \mathrm{kHz}$ falls within the values published by Epoxy Technology, Inc [29]. Frequency of $1 \mathrm{kHz}$ was chosen to have a good comparison with the values published by Epoxy Technology which was done at $1 \mathrm{kHz}$. The measured values were also found to be relatively constant within the vicinity of $1 \mathrm{kHz}$. The neat epoxy has a dielectric constant of 4.30 and loss tangent of 0.019 measured at $1 \mathrm{kHz}$. The addition of fillers produced an increase in the dielectric constant and a decrease in loss tangent $(\tan \delta)$. The loss tangent of the composite with $\mathrm{TiO}_{2}$ nanoparticles reduced to 0.0148 with $2 \mathrm{wt} \%$ concentration of the filler after which the loss tangent began to increase. On the other hand, the loss tangent of the composite with eggshell powder measured at $1 \mathrm{kHz}$ reduced to 0.0153 with $3 \mathrm{wt} \%$ concentration of the filler after which the loss tangent began to increase. The permittivity of the composites was observed to be increasing at low frequencies. An out-of-phase dipole moment 
developed by the charges accumulated at the particles' poles was suggested to be responsible for the behaviour with values that is substantially greater than the derived values from a Maxwell-Wagner theory alone [30]. It may have also been due to favourable mitigation and relaxation of the internal charge as a result of the limited conduction associated with the interaction zones [15].

While the loss tangent of the two composites has comparable lowest values at $1 \mathrm{kHz}$ as shown in Fig. $11 \mathrm{~b}$, the higher dielectric constant of the composites with eggshell powder as shown in Fig. 11a gives it an advantage over the composite with titanium oxide. The loss tangent of microcomposites was reported to be higher than the loss tangent of the neat polymer from previous work [15]. The decrease in the loss tangent of the epoxy microcomposite with eggshell may be linked to the elemental composition of eggshell powder.

Bulk electrical conductivity, $\sigma(\omega)$, in the composites is related to $\tan \delta$ with the following relation [23]:

$\sigma(\omega)=\sigma_{0}+\omega \varepsilon_{0} \varepsilon_{r}^{\prime}(\omega) \tan \delta$,

where $\sigma_{0}$ is the DC conductivity, $\omega$ is the angular frequency, $\varepsilon_{0}$ is the permittivity of vacuum and $\varepsilon_{\mathrm{r}}^{\prime}$ is the relative permittivity of the sample. This evaluates the total loss in the dielectric which is visualized as a combination of DC conductivity and loss due to polarization which is linked to $\tan \delta$ (loss tangent). The $\tan \delta$ values of the composites indicate that the eggshell microcomposite has comparable bulk conductivities with the nanocomposite at $3 \mathrm{wt} \%$ and $2 \mathrm{wt} \%$, respectively.

The ultimate effect of conduction current process in insulation materials is an electrical breakdown. Therefore, understanding the behaviour of the conduction current at high voltage is very important. AC voltage was

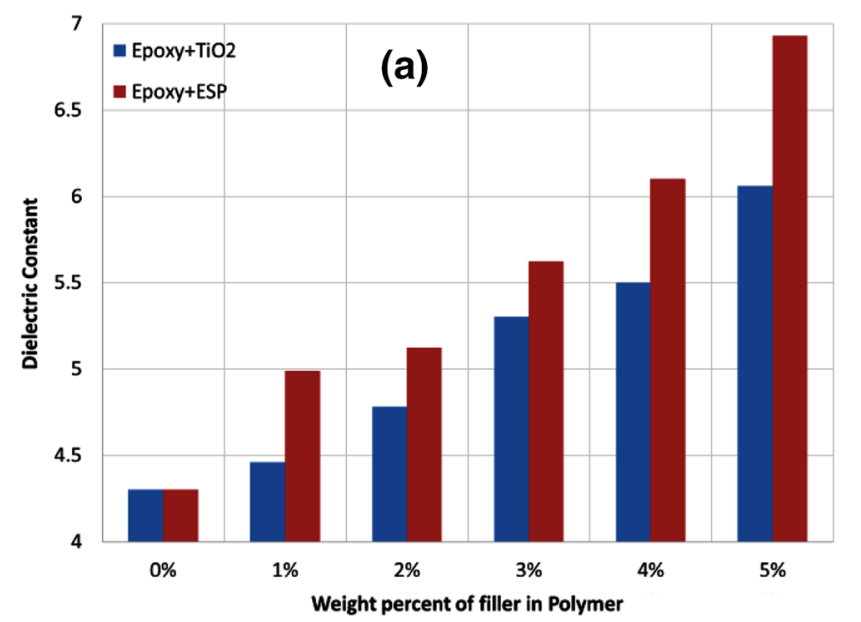

applied to the solid sample, and the current was measured after $1 \mathrm{~min}$. The voltage was increased in a stepwise of $500 \mathrm{~V}$, and the measurement process was repeated. The applied $A C$ voltages versus the $D C$ conduction current measurement results for epoxy/ $/ \mathrm{TiO}_{2}$ polymer nanocomposite and epoxy/eggshell polymer microcomposite are shown in Figs. 12 and 13, respectively.

The characteristic curves for all the samples illustrate that the AC leakage current increases approximately linearly with the applied voltage. This is an indication of an ohmic relationship within the voltage range studied. For the composite system, the conduction current is most likely due to charge hopping in the polymer and increases linearly with the applied voltage for the voltage range studied.

Since the leakage current through the samples displayed a nearly linear relation with the applied voltage, the electrical conductance of the samples was evaluated using the slope of the plots (i.e. by taking the inverse of the slope). The conductance was plotted against weight per cent of filler content in the samples. Both epoxy- $\mathrm{TiO}_{2}$ and epoxy-eggshell polymer composites displayed a decrease in electrical conductance with increasing filler concentration to a certain level after which the electrical conductance began to increase with further increase in filler concentration as shown in Fig. 14. Epoxy- $\mathrm{TiO}_{2}$ nanocomposite gave minimum conductance of $4.0532 \times 10^{-9} \mathrm{~S}$ with $2 \mathrm{wt} \% \mathrm{TiO}_{2}$ nanoparticle. Meanwhile, the epoxy-eggshell powder composite gave minimum conductance of $2.6784 \times 10^{-9} \mathrm{~S}$ with 3 wt $\%$ eggshell particles. The minimum electrical conductance of the eggshell powder polymer composite is lower than that of $\mathrm{TiO}_{2}$ polymer composite. This suggests that epoxy polymer reinforced with eggshell

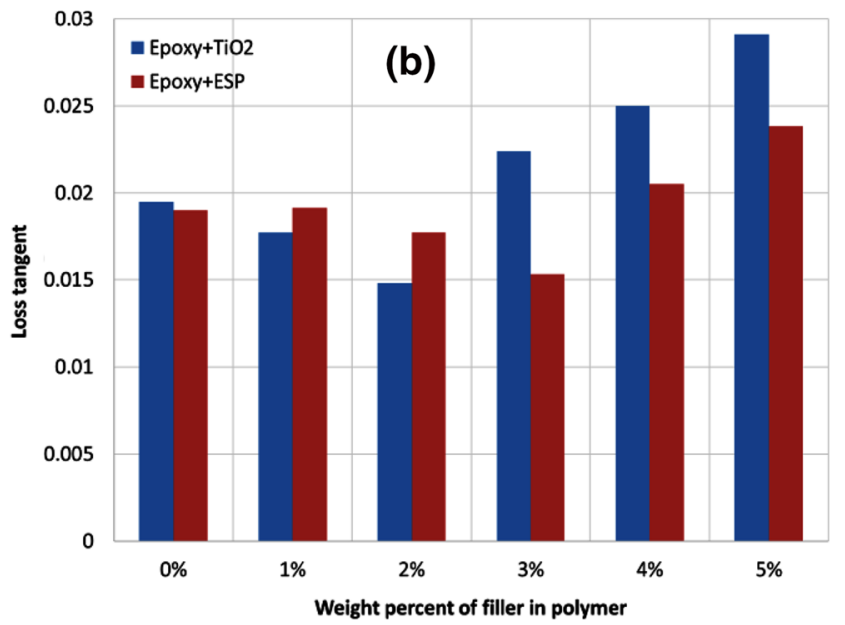

Fig. 11 a Dielectric constant against weight per cent of filler in polymer samples, b loss tangent against weight per cent of filler in polymer samples 
Fig. 12 Conduction current measurements for epoxy/ $/ \mathrm{TiO}_{2}$ polymer nanocomposite
Fig. 13 Conduction current measurements for epoxy/eggshell polymer microcomposites
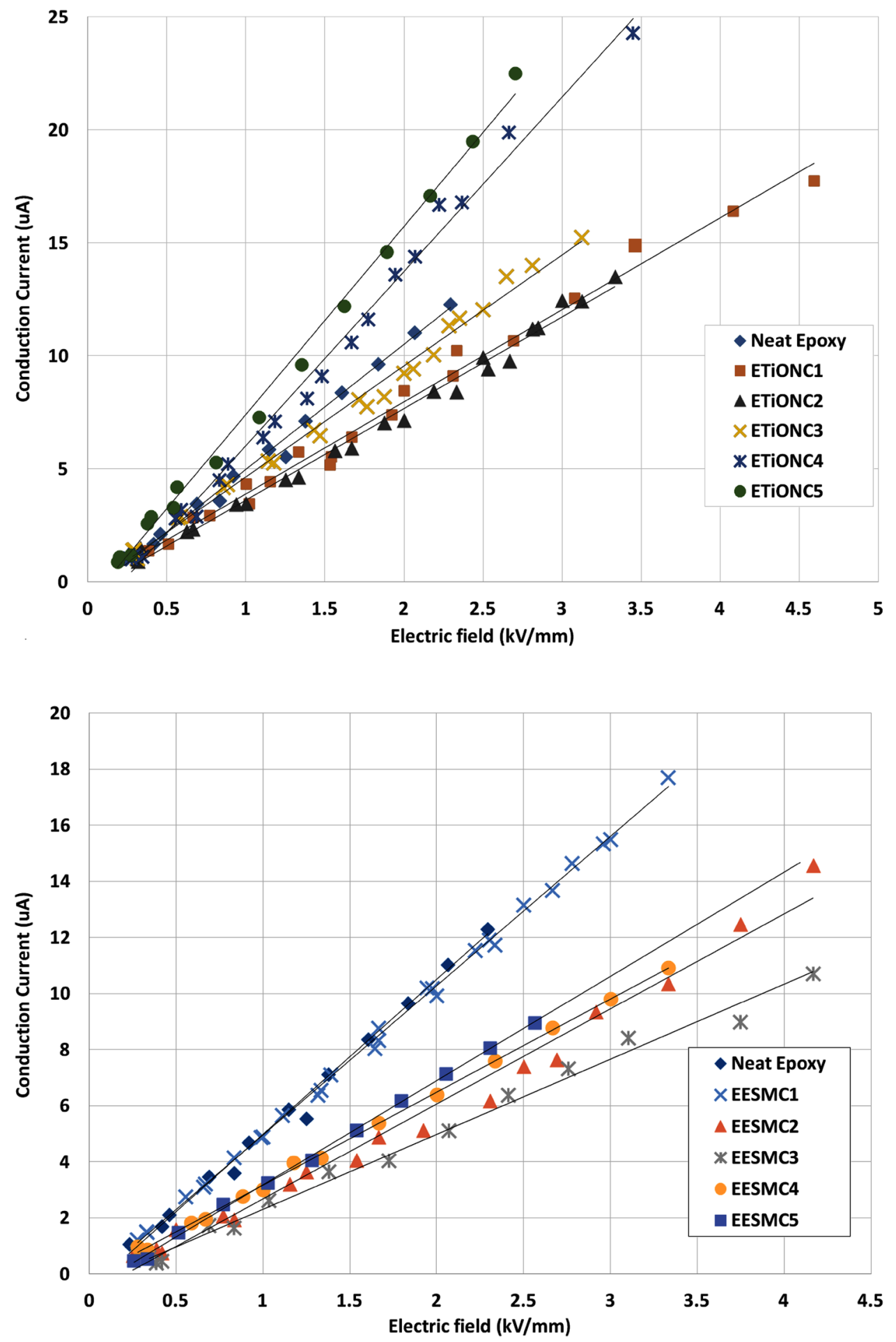

particles produced better electrical insulating material than epoxy polymer reinforced with $\mathrm{TiO}_{2}$ nanoparticles.

The results obtained are similar to earlier work on DC conductivity of low-density polyethylene (LLDPE) and polyimide nanocomposites. $\mathrm{TiO}_{2}$ nanofillers from 1 to $5 \mathrm{wt} \%$, in LLDPE on high-voltage DC, were reported to have displayed a significant increase in conduction current. $\mathrm{TiO}_{2}$ nanofiller in polyimide shows a decrease in DC conductivity up to $3 \mathrm{wt} \%$, and the conductivity began to increase with the sample containing $5 \mathrm{wt} \%$ of the nanoparticle. The conduction current of alumina nanoparticles-filled LLDPE samples also decreases with an increase in percentage concentration of nanofiller up to $3 \mathrm{wt} \%$, beyond which conduction current began to increase significantly 
Fig. 14 Electrical conductance against weight per cent of filler in polymer samples

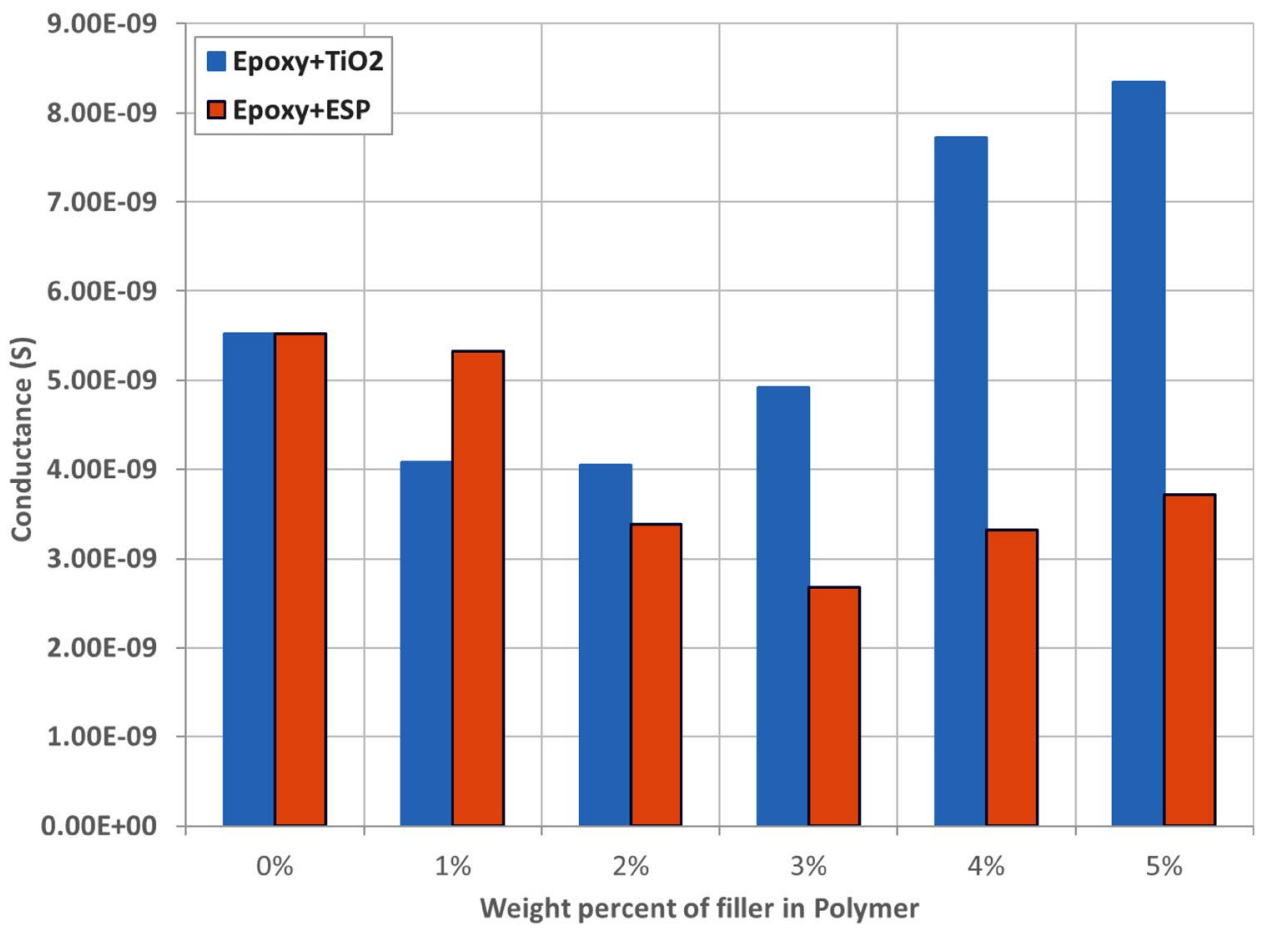

compared to the neat polyethylene [17]. This trend is quite similar to what was obtained for epoxy that was filled with eggshell powder that is about $77 \%$ calcium oxide. This is an indication that the addition of up to $3 \mathrm{wt} \%$ of the fillers provides the optimum hindrance to the movement of charges in the bulk of the material. Beyond $3 \mathrm{wt} \%$, there may be an onset of some charge injection processes that may have resulted in more conduction processes, thereby leading to an increase in conductivity.

\section{Conclusions}

The obtained values for epoxy- $\mathrm{TiO}_{2}$ nanocomposite were comparable to the earlier reported results for similarly prepared samples. The eggshell-filled epoxy polymer has tensile strength improved by $22.4 \%$ with $4 \%$ filler. The tensile strength is slightly lower than that of $\mathrm{TiO}_{2}$ nanoparticlefilled epoxy whose tensile strength improved by $69.5 \%$ with 3\% filler. The lower tensile strength of eggshell-filled epoxy composite as compared with the $\mathrm{TiO}_{2}$-filled epoxy composite is likely related to the size and number of the dispersed eggshell particles in the polymer matrix. The eggshell displayed higher thermal conductivity, an indication that the eggshell filler improved the heat dissipation properties of epoxy polymer. The epoxy composite systems with the eggshell powder fillers displayed some advantageous dielectric behaviours at low filler loadings. The eggshell-epoxy polymer composite has a higher dielectric constant and comparable loss tangent with
$\mathrm{TiO}_{2}$ nanocomposite, but the electrical conductance of eggshell-epoxy composites at high voltage was found to be lower than that of $\mathrm{TiO}_{2}$ nanocomposite as well as the unfilled polymer. The samples prepared with eggshell powder displayed a decrease in conductance up to $3 \mathrm{wt} \%$ concentration, an indication of improved properties as an electrical insulation material. The results suggest that eggshell powder as a filler could produce composite polymeric insulation with improved properties. There may be the need for further processing of the eggshell particles to smaller sizes to study the effect of particle size and interparticle distance between dispersed particles to further understand their dielectric behaviour.

Acknowledgements The authors wish to acknowledge the contribution of Mr. Bilyaminu Ibrahim for setting up the laboratory for dielectric measurements. They also wish to acknowledge Mr. Nura Lawal for his contribution towards putting up the high-voltage measurement set-up.

\section{Compliance with ethical standards}

Conflict of interest The authors declare that they have no conflict of interest.

\section{References}

1. Massingill Jr JL, Bauer RS (2000) Epoxy resins. In: Craver CD, Carraher Jr CE (ed.) Applied polymer science: 21st century. Elsevier, Amsterdam, pp 393-424 
2. Woods EE, Heinrichs FW (1963) Cast epoxy insulation for high voltage switchgear and power transformers. In: El electrical insulation conference materials and application, pp 265-266. https ://doi.org/10.1109/eic.1963.7461803

3. Jaya A, Berahim H, Rochmadi T (2012) The performance of high voltage insulator based on epoxy-polysiloxane and rice husk ash compound in tropical climate area. Electr Electron Eng 4:208-216. https://doi.org/10.5923/j.eee.20120204.06

4. Smith PA, Yeomans JA (2009) Benefits of fiber and particulate reinforcement. Mater Sci Eng 2:133-154

5. Barber P, Balasubramanian S, Anguchamy Y, Gong S, Wibowo A, Gao H, Ploehn HJ, Loye H (2009) Polymer composite and nanocomposite dielectric materials for pulse power energy storage. Materials 2:1697-1733. https://doi.org/10.3390/ma2041697

6. Lan T, Pinnavaia TJ (1994) Clay-reinforced epoxy nanocomposites. Chem Mater 6:2216-2219

7. Hui L, Smith R, Nelson JK, Schadler LS (2009) Electrochemical treeing in XLPE/silica nanocomposites. In: IEEE conference on electrical insulation and dielectric phenomena. https://doi. org/10.1109/ceidp.2009.5377858

8. Shah KS, Jain RC, Shrinet V, Singh AK (2009) High-density polyethylene (HDPE) clay nanocomposite for dielectric applications. IEEE Trans Dielectr Electr Insul 16(3):853-861

9. Tuncer E, Sauers I, Randy D, Ellis AR, Paranthaman MP, Goyal A, More KL (2007) Enhancement of dielectric strength in nanocomposites. Nanotechnology 18:325704

10. Zhang C, Stevens GC (2008) The dielectric response of polar and non-polar nanodielectrics. IEEE Trans Dielectr Electr Insul 15(2):606-617

11. Wang HW, Dong RX, Liu CL, Chang HY (2007) Effect of clay on properties of polyimide-clay nanocomposites. J Appl Polym Sci. https://doi.org/10.1002/app.25740

12. Nelson JK, Hu Y (2005) Nanocomposite dielectrics-properties and implications. J Phys D Appl Phys 38:213-222

13. Singha S, Thomas MJ (2008) Permittivity and tan delta characteristics of epoxy nanocomposites. IEEE Trans Dielectr Electr Insul 15(1):106-117

14. Singha S, Thomas MJ (2008) Reduction of permittivity in epoxy nanocomposites at low nano-filler loadings. In: Annual report conference on electrical insulation dielectric phenomena, $\mathrm{pp}$ 726-729

15. Singha S, Thomas MJ (2008) Dielectric properties of epoxy nanocomposites. IEEE Trans Dielectr Electr Insul 15(1):12-23

16. Nelson JK, Fothergill JC (2004) Internal charge behaviour of nanocomposites. Nanotechnology 15:586-595

17. Mohd Jamail NA, Mohamed Piah MA, Muhamad NA, Zainir RA, Kasri N, Kamarudin QE (2013) DC conductivity of polymer nanocomposites for different types and amount of nanofiller. Int J Electric Eng Inform 5(2):217-225
18. LiY, Xin S, Bian Y, Xu K, Han C, Dong L (2016) The physical properties of poly(L-lactide) and functionalized eggshell powder composites. Int J Biol Macromol 85:63-73. https://doi.org/10.1016/j. ijbiomac.2015.12.070

19. Bashir ASM, Manusamy Y (2015) Characterization of raw eggshell powder (esp) as a good bio-filler. J Eng Res Technol 2(1):56-60

20. Freire MN, Holanda JNF (2006) Characterization of avian eggshell waste aiming its use in a ceramic wall tile paste. Cerâmica 52:240-244

21. Jirimali HD, Chaudhari BC, Khanderay JC, Joshi SA, Singh V, Patil AM, Gite VV (2018) Waste eggshell-derived calcium oxide and nanohydroxyapatite biomaterials for the preparation of LLDPE polymer nanocomposite and their thermomechanical study. Polym Plast Technol Eng 57(8):804-811. https://doi. org/10.1080/03602559.2017.1354221

22. Abdelmalik AA, Sadiq A (2019) Thermal and electrical characterization of composite metal oxides particles from periwinkle shell for dielectric application. SN Appl Sci 1:373. https://doi. org/10.1007/s42452-019-0388-5

23. Von Hippel AR (1956) Theory in dielectric materials and applications. The MIT Press, Cambridge, pp 3-46

24. Witoon T (2011) Characterization of calcium oxide derived from waste eggshell and its application as $\mathrm{CO}_{2}$ sorbent. Ceram Int 37:3291-3298

25. Suja CP, Senthil SL, Jeyatha B, Ponmalar J, Mary K (2008) First characterization report of natural pearl of Pinctada fucata from Gulf of Mannar. Biotechnol Res Innov 2:58-62

26. Kamba AS, Ismail M, Ibrahim TAT, Zakaria ZA (2013) Synthesis and characterisation of calcium carbonate aragonite nanocrystals from cockle shell powder (Anadara granosa). J Nanomater. https://doi.org/10.1155/2013/398357

27. Kausch HH, Michler GH (2007) Effect of nanoparticle size and size-distribution on mechanical behavior of filled amorphous thermoplastic polymers. J Appl Polym Sci 105(5):2577-2587. https://doi.org/10.1002/app.26570

28. Garrett KW, Rosenberg HM (1974) The thermal conductivity of epoxy resin/powder composite materials. J Phys D Appl Phys 7:1247-1258

29. Epoxy Technology, Dielectric Properties of Epoxies, Epoxy Technology Inc. (2014). http://www.epotek.com/site/files/Techtips/ pdfs/Tech_Tip_25_-_Dielectric_Properties_of_Epoxies.pdf

30. Lewis TJ (2004) Interfaces and nanodielectrics are synonymous. Proc IEEE Int Conf Solid Dielectr 2:792-795

Publisher's Note Springer Nature remains neutral with regard to jurisdictional claims in published maps and institutional affiliations. 